\title{
Zygomycosis: A Highly Infectious Emerging Opportunistic Fungal Disease of Public Health Concern
}

\section{Pal M* \\ Director of Veterinary Public Health and Microbiology, India}

*Corresponding author: Mahendra Pal, Founder Director of Narayan Consultancy on Veterinary Public Health and Microbiology, Anand, Gujarat, India, Email: palmahendra2@ gmail.com

\section{Review Article}

Volume 3 Issue 1

Received Date: May 14, 2020

Published Date: June 08, 2020

DOI: $10.23880 /$ oajmms-16000122

\section{Abstract}

Due to growing numbers of immunocompromised individuals, there is a global rise in the incidence of fungal diseases, especially the opportunistic mycoses. Zygomycosis is an emerging and re-emerging opportunistic mycosis that is caused by ubiquitously occurring filamentous fungi in the environment. Nosocomial outbreaks of zygomycosis have been recorded in leukemic patients. The disease is reported from many nations of the world including India. The inhalation of spores from the environment is recognized as the common route of transmission. There are evidences to believe that humans and animals may acquire the infection from the saprobic reservoirs. The persons, who are suffering from malignancies, diabetes or undergoing, organ transplantation, and those receiving broad-spectrum antimicrobial drugs, corticosteroid therapy or immunosuppressive agents, are at higher risk to get infection. The direct microscopic demonstration of the pathogen in clinical materials and its isolation in pure and luxuriant form is still considered as the mainstay of diagnosis. The control or reversal of the underlying disease or immunosuppression, antifungal therapy, surgical debridement, and aggressive antifungal therapy remain the gold standard of treatment. An early correct diagnosis and prompt specific antifungal therapy in immunocompromised patients is imperative to prevent the fatal consequences of disease.

Keywords: Emerging Mycosis; Human; Immunosuppression; Opportunistic Pathogen; Public Heath; Zygomycosis

\section{Introduction}

Zygomycosis, also known as Mycormycosis, Phycomycosis, is emerging and re-emerging, opportunistic, highly infectious, life threatening mycosis of humans and animals, and is described from many countries of the world including India Greeberg RN, et al. [1], Brown J, et al. [2], Chayalkeeree M, et al. [3], Padmaja IJ, et al. [4], Carol AK, et al. [5], Pal [6], Skiada A, et al. [7]. Disease is caused by many species of zygomycetes that exist in diverse types of environmental materials like soil, air, decaying organic matter, and contaminated foods Carol AK, et al. [5], Pal M [6]. It is reported that natural disasters, such as tsunami in Southeast Asia, and volcano eruption in Columbia are related with increased number of cutaneous and subcutaneous zygomycosis due to traumatized inoculation of zygomycetes into wounds Skiada A, et al. [7], Mantadakis E, et al. [8]. In India, the first report of fatal pulmonary zygomycosis in chicks due Absidia corymbifera was published by Pal M, et al. [9]. Ribes and co-investigators (2000) are credited to describe the first case of zygomycosis in a cancer patient. There is a rise of zygomycosis cases in cancer hospitals Konoyiannis DP, et al. [10]. A number of factors including diabetes mellitus, leukemia, stem cell recipient, solid organ transplant, prolonged use of broad spectrum antibacterial antibiotics and corticosteroids, malnutrition, emaciation, acidosis, etc. are attributed to predispose the host to infection Chayalkeeree M, et al. [3], Pal M [6], Mantadakis E, 


\section{Open Access Journal of Mycology \& Mycological Sciences}

et al. [8], Skiada A, et al. [7]. It is mentioned that $40 \%$ of the cases are associated with diabetes mellitus. Rhinocerebral zygomycosis is considered a very serious form of the disease with mortality rate of 30 to $70 \%$ Mantadakis E, et al. [8]. Zygomycosis due to Rhizopus oryzae affects over 10,000 persons annually Brown GD, et al. [11]. The objective of this paper is to describe zygomycosis as a highly infectious emerging opportunistic mycosis of public health importance.

\section{Etiology}

Zygomycosis in humans and animals are caused by many fungi, such as Absidia corymbifera, Apophysomyces elegans, Basidiobolus ranarum, Cokeromyces recurvatus, Condiobolus incongrus, Cunnighamella berthollectiae, Mortierella wolfii, Mucor circinelloides, $M$ racemosus, $M$ ramosissimus, Rhizomucor pusillus, $R$ variabilis, Rhizopus microspores, $R$ oryzae, $R$ rhizopodiformis, Saksenaea vasiformis and Syncephalastrum racemonus Padmaja IJ, et al. [4], Pal M [6], Skiada A, et al. [7], Pal M, et al. [9], Romano C, et al. [12], Baradkar VP, et al. [13], Zhao Y, et al. [14], Pal M [15]. These fungi occur as saprobe, and are recovered from air, soil, polluted water, decaying vegetables and fruits, bread, stored grain, wheat, grain, groundnuts, rice, barley, dung, compost, etc. Carol AK, et al. [5], Pal M [6]. The fungi have angioinvasive characteristics to produce haemorrhage, infarction, and thrombosis Pal M [6].

\section{Transmission}

Natural infections due to zygomycetes have been documented in humans and many species of animals Pal $\mathrm{M}$ [6], Pal M, et al. [9], Tania AB, et al. [16], Chander J, et al. [17], Dave P, et al. [18]. Different modes of disease transmission, such as inhalation, ingestion, or traumatic inoculation are reported Pal M [6], Ribes JA, et al. [19]. Contact with fungal contaminated soil and vegetation greatly increases the chances of cutaneous zygomycosis. . Contaminated dressings may sometime cause cutaneous infection due to $R$ rhizopodiformis. The primary cutaneous form of zygomycosis is encountered in burn patients Ledgard JP, et al. [20]. Leeming and co-workers (1996) reported nosocomial transmission of zygomycetes via contaminated tongue depressors. Hitherto, there is no evidence of direct transmission of disease from diseased animals to humans or vice-versa Pal M [6].

\section{Clinical Spectrum}

In humans, several clinical forms, such as cutaneous, subcutaneous, pulmonary, rhino cerebral, gastrointestinal, and systemic zygomycosis are observed. Other unusual forms include endocarditis, pyelonephritis, and osteomyelitis Pal M [6], Mantadakis E, et al. [8]. The patients show severe frontal headache, orbital swelling, nasal discharge, fever, chills, chest pain, sinusitis, blood tinged sputum, superficial ulcer, flat, erythematous, popular, dark yellow, nodular lesion, pustule, ulceration, deep abscess, large, painless, firm mass besides ocular and brain symptoms Pal M [6], Skiada A, et al. [7]. Rhino-orbital-cerebral zygomycosis is most often encountered in patients with diabetes mellitus. Pulmonary zygomycosis can spread to other organs, if prompt therapy is not undertaken Mantadakis E, et al. [8]. Cutaneous lesions are most commonly noticed on the arms and legs, though the skin of any area may be affected Skiada A, et al. [7]. Rarely, the infection has been reported in immunocompetent patient Zhao Y, et al. [14].

\section{Diagnosis}

As clinical signs of zygomycosis are not characteristic to ascertain the diagnosis of disease, therefore, laboratory help is essential to confirm the diagnosis. In human clinical practice, X-ray, computed tomography, and magnetic resonance imaging are useful to detect the lesions in body Pal M [6]. The isolation of the fungus from clinical specimens in pure and luxuriant growth on mycological media (Sabouraud dextrose agar, Pal sunflower seed agar Pal M [21], and APRM (Anubha, Pratibha, Raj, Mahendra) agar Dave P, et al. [18], and its direct microscopic detection as hyaline, broad, acetate hyphae in the wet mount, $\mathrm{KOH}$ (potassium hydroxide) preparation, PHOL (Pal, Hasegawa, Ono, Lee) stain Pal M, et al. [22], Narayan stain Pal M [23], Gram`s stain, Giemsa stain are still considered the golden standard of diagnosis. In addition, histopathologic (GrocottGomori's methylamine silver stain, Periodic acid-Schiff stain), immunological (ELISA, Immuno diffusion), and molecular (Polymerase chain reaction, Restriction fragment length polymorphism analyses) techniques are also employed for diagnosis of zygomycosis Pal M [6], Dannaoui E, et al. [24], Leeming LG, et al.[25]. The disease should be differentiated from aspergillosis, elephantiasis, onchocercariasis, and sprout rachises Pal M [6]. It is pertinent to mention that cycloheximide, should not be included into the media, as it will suppress the growth of zygomycetes Pal M [6].

\section{Management}

The treatment of zygomycosis is challenging, and therefore, a multifaceted approach that include antifungal therapy, surgical debridement and elimination of predisposing factors is needed Carol AK, et al. [5]. As zygomycetes are resistant to echinocandins, terbinafine, and Flucytosine, liposomal amphotericin B is considered the main stay of treatment of disease. Quick surgical debridement of infected and necrotic tissues and administration of liposomal amphotericin-B (3-5 mg/kg body weight) helps to mitigate the morbidity of disease. Very recently, posaconazole, a broad spectrum antifungal drug, has shown encouraging results in zygomycosis Rutar $\mathrm{T}$, et al. [26]. The prognosis of 


\section{Open Access Journal of Mycology \& Mycological Sciences}

rhinocerebral, pulmonary, and disseminated zygomycosis remains poor. In the absence of commercially available vaccines, the prevention of disease depends on correcting the predisposing factors, use of face mask by Immuno compromised persons when visiting heavily polluted environment, early recognition of disease, and prompt therapy.

\section{Conclusion}

Zygomycosis has emerged as an important nosocomial mycosis of global public health concern. Cutaneous zygomycosis is one of the most common clinical presentations of the disease. Combination of liposomal amphotericin $B$ and posaconazole showed encouraging results in the management of disease. The wider use of Pal sunflower seed medium, APRM agar, PHOL stain, Narayan stain for the studies of fungi including zygomycetes in microbiology and public health laboratories is recommended. Further studies to elucidate the etiologic role of zygomycetes in different clinical conditions of humans and animals seem highly imperative.

\section{Acknowledgement}

The author is highly grateful to Prof. Dr. RK Narayan for critically going through the manuscript. The computer help of Anubha Priyabandhu is highly appreciated.

\section{References}

1. Greenberg RN, Scott LJ, Vaughn HH (2004) Zygomycosis (Mucormycosis): emerging clinical importance and new treatments. Curr Opin Infec Dis 17(6): 517-525.

2. Brown J (2005) Zygomycosis: an emerging fungal infection. Am J Health Syst Pharm 62(24): 2593-2596.

3. Chayakulkeeree M, Ghannoum MA, Perfect JR (2006) Zygomycosis: the re-emerging fungal infection. Eur J Clin Microbiol Infect Dis 25(4): 215-229.

4. Padmaja IJ, Ramani TV, Kalyani S (2006) Cutaneous zygomycosis: Necrotizing fasciitis due to Saxenaea vasiformis. Indian J Med Microbiol 24(1): 58-60.

5. Carol AK, Anurag NM (2007) Zygomycosis: An emerging fungal infection with new options for management. Curr Infect Dis Rep 9(6): 435-440.

6. Pal M (2007) Veterinary and Medical Mycology. $1^{\text {st }}$ (Edn.), Indian Council of Agricultural Research, New Delhi, India.

7. Skiadan A, Rigopoulos D, Larios G, Petrikkos G, Katsambas A (2012) Global epidemiology of cutaneous zygomycosis. Clin Dermatol 30(6): 628-632.

8. Mantadakis E, Samonis G (2009) Clinical presentation of zygomycosis. Clinical Microbiology and Infection 15(S5): 15-20.

9. Pal M, Lee CW (1994) Pulmonary zygomycosis in chicks due to Absidia corymbifera. Korean Journal of Veterinary Clinical Medicine 11(1): 1-3.

10. Kontoyiannis DP, Wessel VC, Bodey GP, Rolston KV (2000) Zygomycosis in the $1990 \mathrm{~s}$ in a tertiary-care cancer centre. Clinical Infectious Diseases 30(6): 851-856.

11. Brown GD, Denning DW, Gow NAR, Levitz SM, Netea MG (2012) Hidden killers: Human fungal infections. Science Translation Medicine 4(165): 165.

12. Romano C, Miracco C, Massai L, Piane R, Alessandrini C, et al. (2004) Fatal rhinocerebral zygomycosis due to Rhizopus oryzae. Mycoses 45(1-2): 45-49.

13. Baradkar VP, Kumar S (2009) Cutaneous zygomycosis due to Saksenaea vasiformis in an immunocompetent host. Indian J Dermatol 54(4): 382-384.

14. Zhao Y, Zhang Q Li L, Zhu J, Kang K, Chen L (2009) Primary cutaneous mucormycosis caused by Rhizomucor variabilis in an immunocompetent patient. Mycopathologia 168(5): 243-247.

15. Pal M (2015) Grwoing role of fungi in mycotic abortion of domestic animal. Journal of Bacteriology and Mycology 2(1): 1009.

16. Tania AB, Roy AR, Dima D, Souha SK, Zeina AK (2011) Three cases of mycormycosis from Middle East: Different risk factors leading to different outcomes. Journal of Invasive Fungal Infection 5(4): 118-122.

17. Chander J, Kaur J, Attri A, Mohan H (2010) Primary cutaneous zygomycosis from a tertiary care centre in north-west India. Indian J Med Res 131: 765-770.

18. Dave P, Pal M (2015) New medium "APRM" for isolation of medically important fungi from clinical and environmental samples. Int J Livest Res 5(3): 10-18.

19. Ribes JA, Vanover Sams CL, Baker DJ (2000) Zygomycosis in human disease. Clin Microbiol Rev 13(2): 236-301.

20. Ledgard JP, van Hala S, Greenwood JE (2008) Primary cutaneous zygomycosis in a burns patient: a review. J Burn Care Res 29(2): 286-290.

21. Pal M (1997) Use of Pal's sunflower seed medium for an early diagnosis of cryptococcosis. The Antiseptic 95(5): 


\section{Open Access Journal of Mycology \& Mycological Sciences}

175.

22. Pal M, Hasegawa A, Ono K, Lee CW (1990) A new staining solution for the morphological studies of fungi and Prototheca. Japanese Journal of Veterinary Research 52(3): 527-531.

23. Pal M (2004) Efficacy of Narayan stain for the morphological studies of moulds, yeasts and algae. Rev Iberoam Micol 21(4): 219.
24. Dannaoui E (2009) Molecular tools for identification of zygomycetes and the diagnosis of zygomycosis. Clinical Microbiology and Infection 15(S5): 66-70.

25. Leeming LG, Moss HA, Elliott TS (1996) Risk of tongue depressors to the immunocompromised. The Lancet 348(9031): 889.

26. Rutar T, Cockerman KP (2006) Periorbital zygomycosis (mucormycosis) treated with posaconazole. American Journal of Ophthalmology 142(1): 187-188.

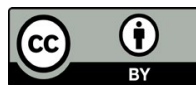

